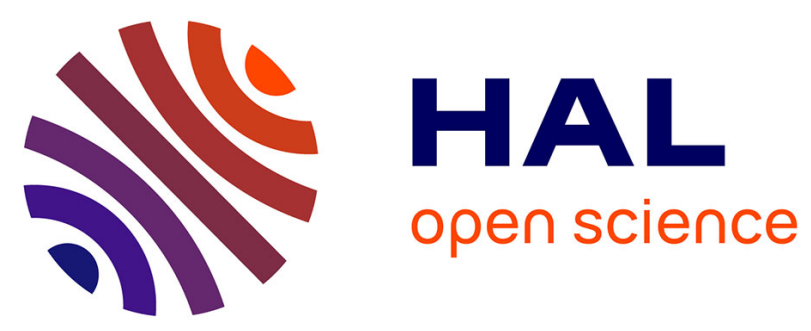

\title{
Evidence of Superparamagnetic Co Clusters in Pulsed Laser Deposition-Grown Zn 0.9 Co 0.1 O Thin Films Using Atom Probe Tomography
}

Rodrigue Larde, Etienne Talbot, Philippe Pareige, Herrade Bieber, Guy Schmerber, Silviu Colis, Veronique Pierron-Bohnes, Aziz Dinia

\section{To cite this version:}

Rodrigue Larde, Etienne Talbot, Philippe Pareige, Herrade Bieber, Guy Schmerber, et al.. Evidence of Superparamagnetic Co Clusters in Pulsed Laser Deposition-Grown Zn 0.9 Co 0.1 O Thin Films Using Atom Probe Tomography. Journal of the American Chemical Society, 2011, 133 (5), pp.1451-1458. 10.1021/ja108290u . hal-01633468

\section{HAL Id: hal-01633468 https://hal.science/hal-01633468}

Submitted on 16 Jan 2019

HAL is a multi-disciplinary open access archive for the deposit and dissemination of scientific research documents, whether they are published or not. The documents may come from teaching and research institutions in France or abroad, or from public or private research centers.
L'archive ouverte pluridisciplinaire HAL, est destinée au dépôt et à la diffusion de documents scientifiques de niveau recherche, publiés ou non, émanant des établissements d'enseignement et de recherche français ou étrangers, des laboratoires publics ou privés. 


\title{
Evidence of Superparamagnetic Co Clusters in Pulsed Laser Deposition-Grown $\mathrm{Zn}_{0.9} \mathrm{Co}_{0.1} \mathrm{O}$ Thin Films Using Atom Probe Tomography
}

\author{
Rodrigue Lardé, ${ }^{*+}$ Etienne Talbot, ${ }^{\dagger}$ Philippe Pareige, ${ }^{\dagger}$ Herrade Bieber, ${ }^{\ddagger}$ Guy Schmerber, ${ }^{\ddagger}$ Silviu Colis, ${ }^{\neq}$ \\ Véronique Pierron-Bohnes, ${ }^{\ddagger}$ and Aziz Dinia ${ }^{\ddagger}$ \\ ${ }^{\dagger}$ Groupe de Physique des Matériaux (GPM), UMR 6634 CNRS, Université et INSA de Rouen, \\ Avenue de l'Université, B.P. 12, 76801 Saint Etienne du Rouvray, France \\ ${ }^{\ddagger}$ Institut de Physique et Chimie des Matériaux (IPCMS), UMR 7504 CNRS-UDS, 23 rue du Loess, B.P. 43, \\ 67034 Strasbourg Cedex 2, France
}

\begin{abstract}
Nanosized Co clusters (of about $3 \mathrm{~nm}$ size) were unambiguously identified in Co-doped ZnO thin films by atom probe tomography. These clusters are directly correlated to the superparamagnetic relaxation observed by ZFC/FC magnetization measurements. These analyses provide strong evidence that the room-temperature ferromagnetism observed in the magnetization curves cannot be attributed to the observed Co clusters. Because there is no experimental evidence of the presence of other secondary phases, our results reinforce the assumption of a defect-induced ferromagnetism in Co-doped $\mathrm{ZnO}$ diluted magnetic semi-conductors.
\end{abstract}

Tn the field of spintronics, the main challenge for the development of a new electronic device technology is to reach an efficient injection of spin-polarized current into semiconductors. Although this spin-injection could be realized from metallic ferromagnetic electrodes, this is particularly difficult due to the difference of resistivity between metals and semiconductors, which leads to an accumulation of spin-polarized carriers at the metal-semiconductor interface. Diluted magnetic semiconductors (DMS) appear to be the most promising materials to overcome this difficulty. Such materials, where transition metal atoms (magnetic dopants) are introduced into the cationic sites of a semiconducting host lattice, are close to materials used in microelectronics and exhibit simultaneously semiconducting and ferromagnetic properties. ${ }^{1,2}$ Considerable research efforts have been focused in this area in recent years. The first works on DMS have been focused on $\mathrm{Mn}$ doped III-V compounds such as $\mathrm{Ga}(\mathrm{Mn}) \mathrm{As}^{3}{ }^{3}$ which is, today, the most well understood DMS. $\mathrm{Ga}(\mathrm{Mn})$ As is a p-type semiconductor, which exhibits intrinsic ferromagnetic properties. However, its highest reported Curie temperature is only about $173 \mathrm{~K},{ }^{4}$ far below room temperature, and constitutes the main obstacle for practical applications. For this reason, efforts were focused on developing some materials exhibiting room temperature ferromagnetism. Since the theoretical predictions of Dietl et al. ${ }^{5}$ and Sato et al. ${ }^{6}$ of the existence of RT ferromagnetism in oxide-based wide band gap semiconductors such as $p$-type $\mathrm{Mn}$-doped $\mathrm{ZnO}$ and $n$-type Co-doped $\mathrm{ZnO}$, a large amount of experimental data, especially Co-doped $\mathrm{ZnO}$, has been published. ${ }^{2,7}$ Many methods have been used to elaborate DMS. It is noteworthy to cite the case of Co-doped $\mathrm{ZnO}$ where pulsed laser deposition, ${ }^{8}$ magnetron sputtering, ${ }^{9}$ solid state reaction, ${ }^{10}$ coprecipitation technique, ${ }^{11}$ hydrothermal technique, ${ }^{12}$ molecular beam epitaxy, ${ }^{13}$ mechanosynthesis, ${ }^{14}$ sol-gel technique, ${ }^{15}$ and ion implantation ${ }^{16}$ have been used. However, the understanding of the experimental data is nowadays still confused because of contradictory results. Several studies claim the nonferromagnetic behavior of Co-doped $\mathrm{ZnO},{ }^{17-22}$ whereas other groups suggest ferromagnetic properties for the same compounds. ${ }^{23-30}$

Moreover, the origin and mechanism of the observed ferromagnetic behavior are still a matter of intense debates. In many reports, the ferromagnetic properties are attributed to the dilute phase $^{23,24}$ and to the carrier-mediated exchange mechanism, whereas others suggest that the ferromagnetism originates from the formation of cobalt clusters or secondary phases ${ }^{19,31^{-}-38}$ (like CoZn, $\left.\mathrm{Co}_{3} \mathrm{O}_{4}\right)$. Coey et al. $^{39}$ have also proposed a defect-induced ferromagnetic exchange mechanism based on bond magnetic polarons, and recent theoretical works have shown that $\mathrm{Co}^{2+}-$ oxygen vacancy pairs are able to promote long-range ferromagnetic coupling in the presence of n-type doping. ${ }^{40}$ In this controversial context, everybody agrees that a careful correlation between microstructure and magnetic properties is required to determine the origin of the ferromagnetic properties in DMSs. It is well-known that conventional characterization techniques such as $\mathrm{X}$-ray diffraction (XRD) are not sensitive enough to detect and analyze nanoscale precipitates of Co compounds ( $\mathrm{Co}-\mathrm{Zn}$ binary alloys), Co oxide $\left(\mathrm{Co}_{3} \mathrm{O}_{4}\right)$, or metallic $\mathrm{Co}$ in Co-doped $\mathrm{ZnO}$ samples with Co concentrations lower than $10 \%$. Therefore, several sophisticated methods such as high-resolution transmission electron 
microscopy (HRTEM), ${ }^{41,42}$ electron energy loss spectroscopy (EELS), ${ }^{37,43}$ X-ray absorption spectroscopy (XAS) ${ }^{44}$ X-ray absorption fine structure (XAFS), ${ }^{45}$ and X-ray magnetic circular dichroissm (XMCD) $)^{31,46,47}$ have been used to identify the local structure of low doped DMS.

After the recent development of the laser-assisted atom probe tomography, ${ }^{48}$ it has been shown that oxide materials can be efficiently analyzed by this high-resolution characterization technique. ${ }^{49,50}$ The tomographic atom probe (TAP) is a highresolution analytical microscope, which provides a 3D mapping at the atomic scale of the spatial distribution of atoms in the analyzed specimen. ${ }^{51-53}$ Nowadays, this technique is increasingly used in different nanoscience domains. ${ }^{54-60}$ Moreover, due to its $3 \mathrm{D}$ character, TAP is much more versatile and much more adapted to identify small clusters and to analyze chemical inhomogeneities with respect to conventional HRTEM that gives local informations due to its $2 \mathrm{D}$ character.

In a previous work, TAP was used to characterize sputtered $\mathrm{Zn}_{0.95} \mathrm{Co}_{0.05} \mathrm{O}$ thin films exhibiting room temperature ferromagnetism. ${ }^{49}$ It has been shown that in these films the distribution of $\mathrm{Co}$ atoms is homogeneous within the $\mathrm{ZnO}$ matrix, thereby clearly ruling out the presence of metallic Co clusters and the presence of any secondary phase. This result also shows unambiguously that the femtosecond pulsed laser irradiation used for TAP analyses does not lead to the formation of Co clusters. However, it is well-known that the microstructure and the magnetic properties of Co-doped $\mathrm{ZnO}$ films are strongly dependent on the growth method and experimental conditions.

In this Article, we report on the correlation between nanostructure and magnetic properties of Co-doped $\mathrm{ZnO}$ thin film elaborated by pulsed laser deposition (PLD). The aim is to clarify if PLD, due to the high energies involved during deposition, is well suited to grow DMS and that the magnetic properties in such samples originates indeed from Co ions, Co clusters, or other defects present in the host $\mathrm{ZnO}$ matrix. Particular attention is given to the proof of the existence of any magnetic clusters via the TAP technique. Those clusters are often hard to detect due to their small size when explored using "classic" investigations techniques such as XRD, TEM, or XPS. In this study, a $\mathrm{Zn}_{0.9^{-}}$ $\mathrm{Co}_{0.1} \mathrm{O}$ thin film was deposited by PLD on two substrates: a flat conventional $\mathrm{Si}(100)$ substrate and a prepatterned substrate consisting of an assembly of flat-topped Si (100) pillars $(10 \times$ $10 \times 100 \mu \mathrm{m}^{3}$ ). The background pressure in the growth chamber was $4 \times 10^{-8}$ mbar. The PLD was operated using a $\mathrm{KrF}$ excimer laser $(\lambda=248 \mathrm{~nm})$ with a repetition rate of $10 \mathrm{~Hz}$. The laser energy density was fixed at $1 \mathrm{~J} / \mathrm{cm}^{2}$. The deposition was performed at $723 \mathrm{~K}$ under vacuum $\left(2.8 \times 10^{-6}\right.$ mbar $)$ with a $0.17 \mathrm{sccm} \mathrm{N} / \mathrm{O}_{2}$ (artificial air) gas flow. The thickness of the film is about $120 \mathrm{~nm}$. The structural characterization was performed by XRD using a Siemens D5000 diffractometer $(\theta-2 \theta$ scans and rocking curves) equipped with a monochromatic $\mathrm{Cu}$ source $\left(\lambda \mathrm{Cu} \mathrm{K \alpha} \alpha_{1}=0.154056 \mathrm{~nm}\right)$. The $\theta-2 \theta$ scan was performed in unlocked coupled mode $\omega-2 \theta$ (with $\omega=\theta-1^{\circ}$ ) to reduce the $\mathrm{Si}$ substrate signal. The magnetic properties were carried out by SQUID magnetometry. To have more insight on the structural properties of our samples (dopant distribution, presence of small clusters, etc.), TAP measurements were performed on our samples. For such analyses, some silicon pillars were picked off from the wafer, mounted on a stainless steel fine tip needle with conductive epoxy glue, and tip-shaped using a focused Ga ion beam $(30 \mathrm{kV}){ }^{61}$ To reduce Ga implantation and avoid damages in the region of interest, the $\mathrm{Zn}_{0.90} \mathrm{Co}_{0.10} \mathrm{O}$ thin

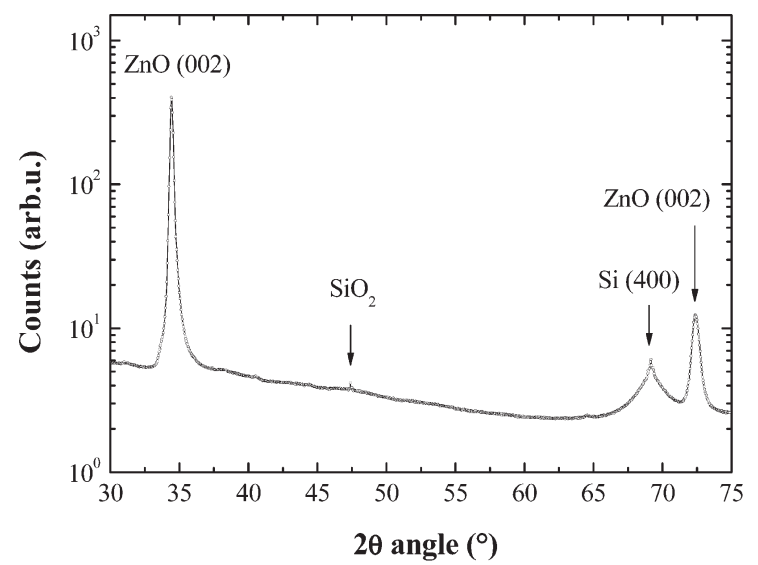

Figure 1. $\omega-2 \theta$ (with $\left.\omega=\theta-1^{\circ}\right) \mathrm{XRD}$ pattern of the $\mathrm{Zn}_{0.9} \mathrm{Co}_{0.1} \mathrm{O}$ thin film.

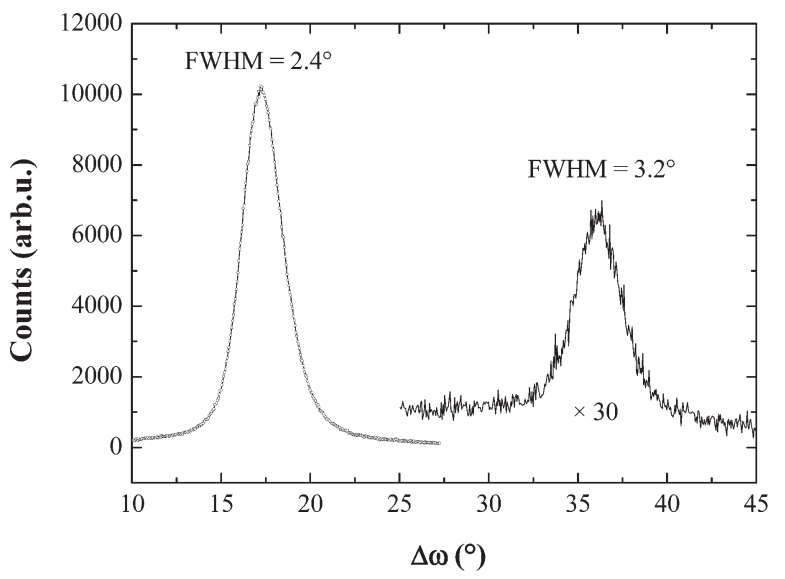

Figure 2. Rocking curve for the 002 (left) and 004 (right) diffraction peaks of the $\mathrm{Zn}_{0.9} \mathrm{Co}_{0.1} \mathrm{O}$ thin film. The rocking curve on the 004 peak is enhanced by a factor of 30 for visibility reasons.

film was capped with $500 \mathrm{~nm}$ of $\mathrm{Cr}$, and the final step of the milling was performed at low acceleration voltage $(2 \mathrm{kV})$. The tips were analyzed by laser-assisted wide-angle tomographic atom probe (LAWATAP) from CAMECA at $80 \mathrm{~K}$ in an ultrahigh vacuum chamber at a pressure of $10^{-9} \mathrm{mbar}$. The femtosecond laser pulse system used was an amplified ytterbium-doped laser (AMPLITUDE SYSTEM s-pulse) with a 350 fs pulse length and a $342 \mathrm{~nm}$ wavelength.

Figure 1 shows the $\mathrm{XRD}$ pattern of the $\mathrm{Zn}_{0.9} \mathrm{Co}_{0.1} \mathrm{O}$ thin film. This pattern contains two peaks (at $34.6^{\circ}$ and $72.9^{\circ}$ ) corresponding to the hexagonal wurtzite $\mathrm{ZnO}$ phase, one peak that can be attributed to $\mathrm{a} \mathrm{SiO}_{2}$ phase, and one peak due to the residual contribution of the Si substrate. No additional diffraction peak corresponding to secondary phases or Co clusters is detected. However, the existence of small clusters cannot be excluded due to the detection limit of the XRD method. The rocking curves recorded on the (002) and (004) $\mathrm{ZnO}$ diffraction peaks are presented in Figure 2. The full widths at half-maximum (fwhm) of the rocking curves are $2.4^{\circ}$ and $3.2^{\circ}$, respectively. This result shows that the $\mathrm{Zn}_{0.9} \mathrm{Co}_{0.1} \mathrm{O}$ thin film is well crystallized, with nanosized grains, and that the growth is quasi-epitaxial with a $c$-axis perpendicular to the film plane.

Figure 3 presents the magnetization loops of the $\mathrm{Zn}_{0.9} \mathrm{Co}_{0.1} \mathrm{O}$ thin film recorded at 300 and $5 \mathrm{~K}$. The diamagnetic contribution 


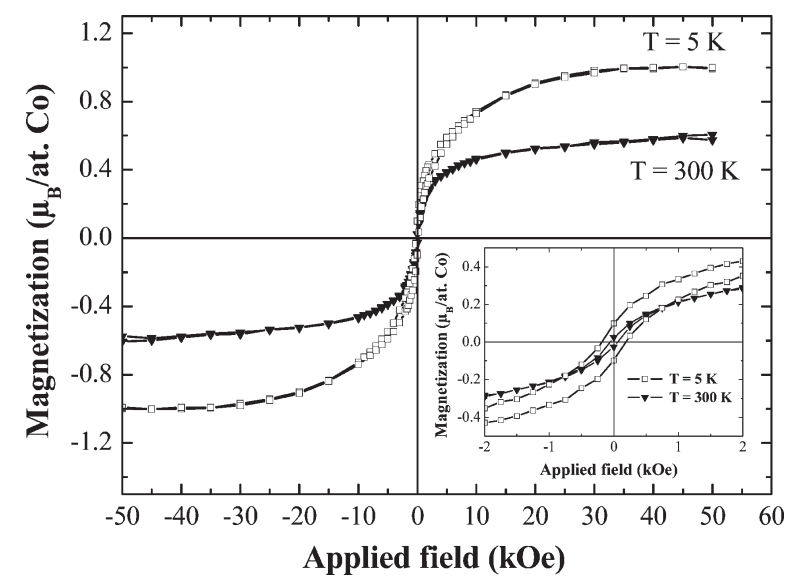

Figure 3. Magnetization hysteresis curves of the $\mathrm{Zn}_{0.9} \mathrm{Co}_{0.1} \mathrm{O}$ thin film. The inset shows a zoom around zero field to evidence the ferromagnetic component of the magnetization in the sample.

was corrected to eliminate the contribution of the Si substrate. This was carried out by correcting the data by a slope equal to the slope of the magnetization loop at high field $(50 \mathrm{kOe})$ and low temperature $(5 \mathrm{~K})$ where the diamagnetic contribution of the substrate is predominant. The same slope correction was applied further to correct the magnetization curve at $300 \mathrm{~K}$. The magnetization curves indicate a ferromagnetic behavior at room temperature characterized by the saturation magnetization $\left(M_{\mathrm{S}}\right) \approx 0.6 \mu_{\mathrm{B}} / \mathrm{Co}$, remanent magnetization $\left(M_{\mathrm{R}}\right) \approx 0.03 \mu_{\mathrm{B}} / \mathrm{Co}$, and coercive field $\left(H_{\mathrm{C}}\right) \approx$ 56 Oe. At $5 \mathrm{~K}, M_{\mathrm{S}} \approx 1 \mu_{\mathrm{B}} / \mathrm{Co}, M_{\mathrm{R}} \approx 0.17 \mu_{\mathrm{B}} / \mathrm{Co}$, and $H_{\mathrm{C}} \approx 218$ Oe. However, the $M_{\mathrm{S}}$ values are much smaller than the $3 \mu_{\mathrm{B}} /$ Co expected for $\mathrm{Co}^{2+}$ ions homogenously dispersed in the $\mathrm{ZnO}$ film. Moreover, the shape of the low temperature magnetization curve as well as the large difference between the room temperature and the low temperature saturation magnetization are a good indication of a paramagnetic contribution of a fraction of the Co ions.

To explore the eventual presence of any superparamagnetic particles in the $\mathrm{Zn}_{0.9} \mathrm{Co}_{0.1} \mathrm{O}$ thin film, zero-field-cooled/field-cooled (ZFC/FC) magnetization curves were recorded under a constant applied magnetic field $H_{\text {appl }}$ of $1 \mathrm{kOe}$ (figure 4). The shape of the obtained ZFC/FC curves is typical for a noninteracting superparamagnetic (SPM) particle assembly with a narrow size distribution. Indeed, the $M_{\mathrm{ZFC}}$ curve exhibits a narrow peak with a maximum temperature $T_{\max }=8 \mathrm{~K}$ and an overlapping with the $M_{\mathrm{FC}}$ curve above an irreversibility temperature $T_{\text {irr }} \approx 20 \mathrm{~K}$. The fact that the irreversibility temperature $\left(T_{\text {irr }}\right)$ is close to $T_{\max }$ shows that the size distribution of the SPM particles is relatively narrow. The exponential decrease of the magnetization when increasing the temperature is a typical signature of superparamagnetic particles. This is in good agreement with the magnetization loops presented above.

It is well-known that the dynamics of a monodispersed nanoparticle assembly is governed by temperature. At high temperature, the magnetic moment of each nanoparticle fluctuates rapidly. Below a characteristic temperature $T_{\mathrm{B}}$, called the blocking temperature, the magnetic moments appear as "blocked". This temperature depends on the anisotropy $(K)$, the volume $(V)$ of the particle, and the specific time of measurement $\left(t_{\mathrm{m}}\right):{ }^{62}$

$$
T_{\mathrm{B}}=\ln \left(\frac{t_{\mathrm{m}}}{\tau_{0}}\right)^{-1} \times \frac{K \cdot V}{k_{\mathrm{B}}}
$$

If we consider that the exponential variation of the magnetic relaxation is sharp and that at a given temperature the blocking

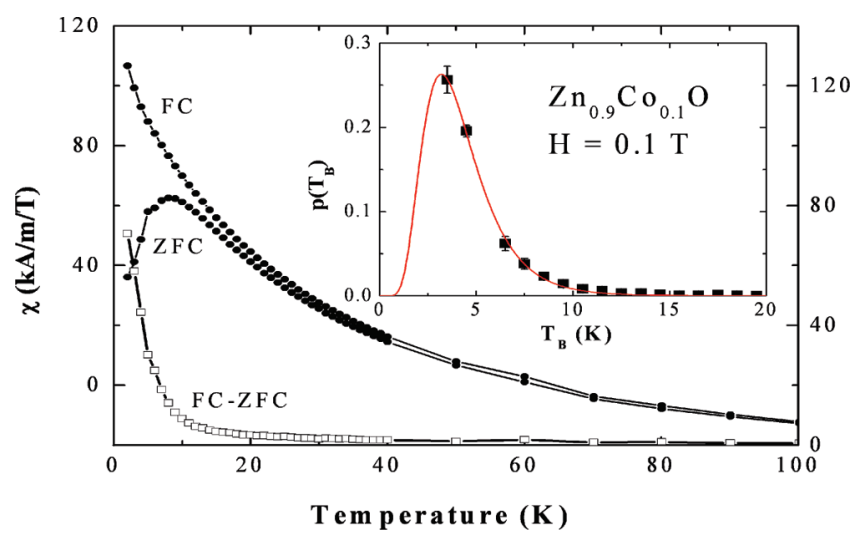

Figure 4. Zero-field-cooled/field-cooled magnetization curves obtained on the $\mathrm{Zn}_{0.9} \mathrm{Co}_{0.1} \mathrm{O}$ thin film with an applied magnetic field of $1 \mathrm{kOe}$. In the inset is shown the blocking temperature distribution estimated from the derivative of the difference of the ZFC/FC curves $(\square)$ divided by $T(\boldsymbol{\square})$ and its adjustment as a log-normal distribution.

volume can be defined as $V_{\mathrm{B}}=k_{\mathrm{B}} T \cdot \ln \left(t_{\mathrm{m}} / \tau_{0}\right) / K$, we can assume, as in the original work of Chantrell, ${ }^{63}$ that all particles with a volume larger than $V_{\mathrm{B}}$ are blocked. These large particles contribute to the total moment by $V H \chi_{\text {ferro }}=\mu_{0} H V M_{\mathrm{S}}^{2} / 3 \mathrm{~K}$ (where $H$ is the magnetic field and $M_{S}$ is the saturation magnetization) if we assume that the anisotropy directions are random and if we consider the transverse susceptibility. In contrast, the particles with a volume smaller than $V_{\mathrm{B}}$ are fluctuating and contribute to the total moment by $V H \chi_{\text {para }}=\mu_{0} H V^{2} M_{\mathrm{S}}^{2} / 3 k_{\mathrm{B}} T$.

We can write:

$$
\begin{aligned}
\mu_{\text {tot }}^{\mathrm{ZFC}} & =\int_{0}^{V_{\mathrm{B}}}\left(\mu_{0} H V^{2} M_{\mathrm{S}}{ }^{2} / 3 k_{\mathrm{B}} T\right) \cdot P(V) \mathrm{d} V \\
& +\int_{V_{\mathrm{B}}}^{\infty}\left(\mu_{0} H V M_{\mathrm{S}}{ }^{2} / 3 K\right) \cdot P(V) \mathrm{d} V
\end{aligned}
$$

where $P(V) \mathrm{d} V$ is the probability to find a particle with a volume between $V$ and $V+\mathrm{d} V$.

Considering that the volume distribution $P(V)$ is associated with a blocking temperature distribution $p(T)$, with $V=k_{\mathrm{B}} T_{\mathrm{B}} \cdot \ln$ $\left(t_{\mathrm{m}} / \tau_{0}\right) / K=\alpha T_{\mathrm{B}}$, we can write:

$$
\begin{aligned}
\mu_{\mathrm{tot}}^{\mathrm{ZFC}} & =\left(\alpha^{2} \mu_{0} H M_{\mathrm{S}}^{2} / 3 k_{\mathrm{B}} T\right) \int_{0}^{T} T_{\mathrm{B}}^{2} \cdot p\left(T_{\mathrm{B}}\right) \mathrm{d} T_{\mathrm{B}} \\
& +\left(\alpha \mu_{0} H M_{\mathrm{S}}^{2} / 3 K\right) \int_{T}^{\infty} T_{\mathrm{B}} \cdot p\left(T_{\mathrm{B}}\right) \mathrm{d} T_{\mathrm{B}}
\end{aligned}
$$

In the FC total moment, the superparamagnetic particles have the same contribution, and the contribution of the blocked particles can be assumed to be that reached by the superparamagnetic particles in the applied field at their blocking temperature:

$$
\begin{aligned}
\mu_{\text {tot }}^{\mathrm{FC}} & =\int_{0}^{V_{\mathrm{B}}}\left(\mu_{0} H V^{2} M_{\mathrm{S}}^{2} / 3 k_{\mathrm{B}} T\right) \cdot p(V) \mathrm{d} V \\
& +\int_{V_{\mathrm{B}}}^{\infty}\left(\mu_{0} H V^{2} M_{\mathrm{S}}^{2} / 3 k_{\mathrm{B}} T_{\mathrm{B}}\right) \cdot p(V) \mathrm{d} V \\
\mu_{\text {tot }}^{\mathrm{FC}} & =\left(\alpha^{2} \mu_{0} H M_{\mathrm{S}}^{2} / 3 k_{\mathrm{B}} T\right) \int_{0}^{T} T_{\mathrm{B}}^{2} \cdot p\left(T_{\mathrm{B}}\right) \mathrm{d} T_{\mathrm{B}} \\
& +\left(\alpha^{2} \mu_{0} H M_{\mathrm{S}}^{2} / 3 k_{\mathrm{B}}\right) \int_{T}^{\infty} T_{\mathrm{B}} \cdot p\left(T_{\mathrm{B}}\right) \mathrm{d} T_{\mathrm{B}}
\end{aligned}
$$




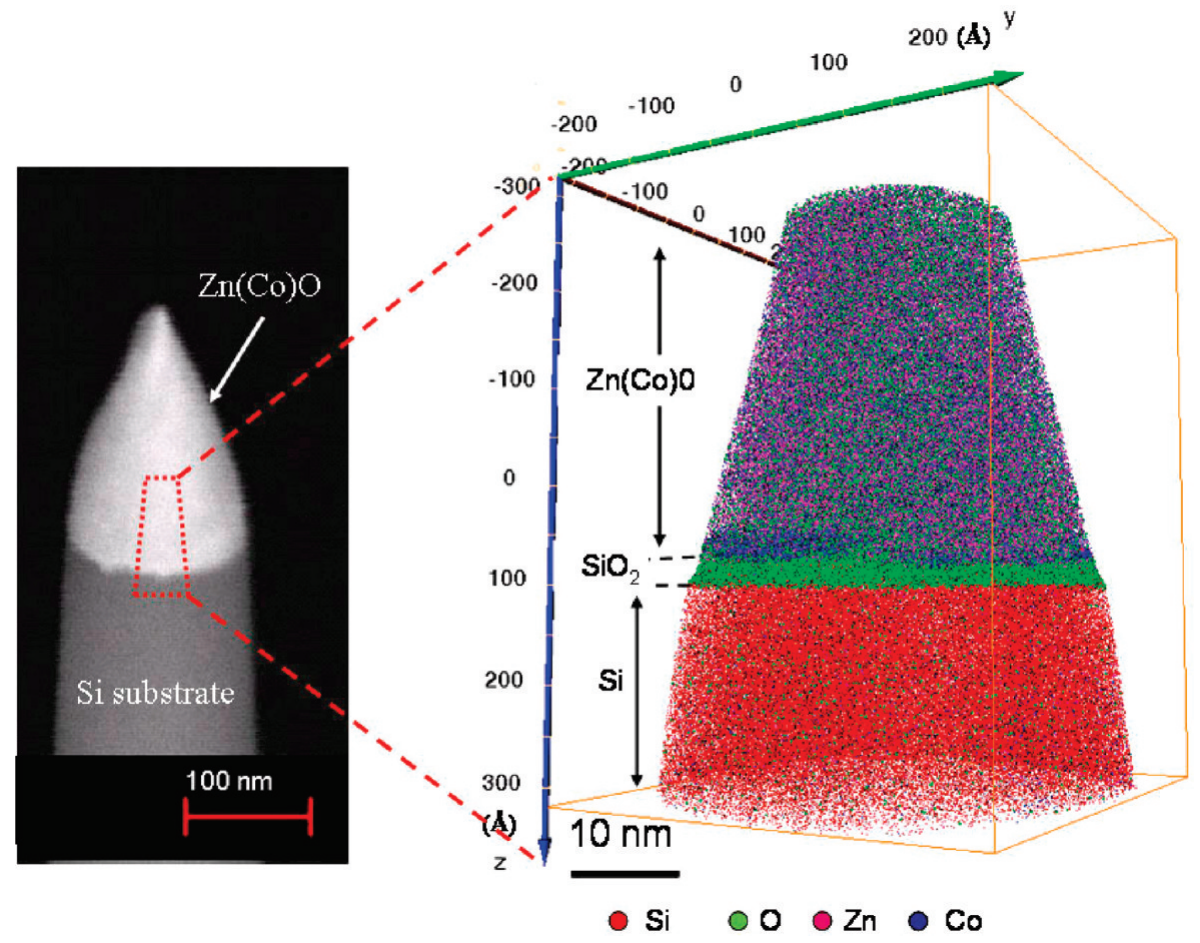

Figure 5. Tip prepared from $\mathrm{Zn}(\mathrm{Co}) \mathrm{O}$ thin film: SEM image on the left and $3 \mathrm{D}$ reconstruction of the analyzed volume obtained by $\mathrm{TAP}$ on the right.

We notice, as Denardin et al., ${ }^{64}$ that the difference between the FC and ZFC curves provides a direct insight on the distribution of the energy barrier $\mathrm{KV}$ ( or $T_{\mathrm{B}}$ ):

$$
\begin{gathered}
\mu_{\mathrm{tot}}^{\mathrm{ZFC}}-\mu_{\mathrm{tot}}^{\mathrm{FC}}=\left(\alpha \mu_{0} H M_{\mathrm{S}}^{2} / 3\right) \\
\times\left(1 / K-\alpha / k_{\mathrm{B}}\right) \int_{T}^{\infty} T_{\mathrm{B}} \cdot p\left(T_{\mathrm{B}}\right) \mathrm{d} T_{\mathrm{B}}=\kappa \int_{T}^{\infty} T_{\mathrm{B}} \cdot p\left(T_{\mathrm{B}}\right) \mathrm{d} T_{\mathrm{B}}
\end{gathered}
$$

Therefore, the blocking temperature distribution (due to the volume distribution) can be accessed after the derivation of the difference between the $\mathrm{ZFC}$ and FC moment subsequently divided by the temperature. The blocking temperature distribution in our sample is shown in the inset of Figure 4. After fitting this distribution to a log-normal distribution $p\left(T_{\mathrm{B}}\right)=A / T_{\mathrm{B}} \cdot \exp -$ $\left(\left(-\ln \left(T_{\mathrm{B}} / T_{\mathrm{B}, \mathrm{C}}\right)^{2}\right) /\left(2 \sigma^{2}\right)\right)$, we get the median temperature $T_{\mathrm{B}, \mathrm{C}}=3.6(1) \mathrm{K}$ and the standard deviation $\sigma=0.47(1)$ of the log-normal distribution. Using $t_{\mathrm{m}}=183 \mathrm{~s}$ and $\tau_{0}=10^{-9}-10^{-10} \mathrm{~s}$, we get $D=3.00(5) \mathrm{nm}$. Note that this method is very useful in cases when there are also other contributions to the moment than the superparamagnetic one. For instance, the ferromagnetic contribution in our sample or ordinary paramagnetic contributions shows the same response in both the FC and the ZFC curves, and, consequently, these contributions disappear by considering the difference of the two curves.

The magnetic measurements show that the magnetic behavior of the $\mathrm{Zn}_{0.9} \mathrm{Co}_{0.1} \mathrm{O}$ thin film is composed of three magnetic components: a ferromagnetic component, a paramagnetic component, and a superparamagnetic component related to the presence of nanosized clusters.

To reveal the presence of Co clusters or secondary phases, the $\mathrm{Zn}_{0.9} \mathrm{Co}_{0.1} \mathrm{O}$ thin film was characterized by tomographic atom probe (TAP). The mass spectrum obtained after the atom probe analysis is similar to that obtained in our previous work on the sputtered $\mathrm{Zn}_{0.95} \mathrm{Co}_{0.05} \mathrm{O}$ thin film. ${ }^{49}$ All peaks could be attributed to the elements constituting the sample. At the end of the analysis, peaks corresponding to $\mathrm{Si}$ and $\mathrm{SiO}_{2}$ appeared on the mass spectrum due to the crossing the $\mathrm{Zn}(\mathrm{Co}) \mathrm{O} /$ substrate interface and the evaporation of $\mathrm{Si}$ atoms of the substrate.

Figure 5 shows a tip shape specimen prepared from the $\mathrm{Zn}(\mathrm{Co}) \mathrm{O}$ thin film by focused ion beam milling (left side) and the $3 \mathrm{D}$ reconstruction of the analyzed volume. Note that in this reconstruction each dot represents one atom. The spatial distribution of all elements ( $\mathrm{Zn}, \mathrm{O}, \mathrm{Co}$, and $\mathrm{Si}$ atoms) can be clearly observed and investigated. In this $3 \mathrm{D}$ volume, we can observe successively the $\mathrm{Zn}(\mathrm{Co}) \mathrm{O}$ layer, the $\mathrm{SiO}_{2}$ layer at the $\mathrm{Zn}(\mathrm{Co}) \mathrm{O} /$ substrate interface, and the Si substrate.

Inside the $\mathrm{Zn}(\mathrm{Co}) \mathrm{O}$ layer, observations and data treatments show that the distribution of all species ( $\mathrm{Zn}, \mathrm{O}$, and $\mathrm{Co}$ ) is homogeneous: no Co cluster and no secondary phases are observed. Co atoms are well dispersed in the $\mathrm{ZnO}$ phase. However, a closer look at the $\mathrm{Zn}(\mathrm{Co}) \mathrm{O} /$ substrate interface reveals a clear Co enrichment (Figure 6) with an inhomogeneous distribution of $\mathrm{Co}$ atoms (Figure 6b). Indeed, when using an iso-concentration representation in the top view of the $\mathrm{Zn}(\mathrm{Co}) \mathrm{O}$ /substrate interface, Co-rich regions containing more than $40 \%$ of Co are observed (Figure $6 \mathrm{~b}$ ).

Several analyses performed on different samples lead to the same conclusion: they all show a Co enrichment at the interface and the presence of an inhomogeneous distribution of Co atoms at the $\mathrm{Zn}(\mathrm{Co}) \mathrm{O} /$ substrate interface. This inhomogeneous distribution corresponds actually to the formation of nanosized Corich clusters, which decorate the $\mathrm{Zn}(\mathrm{Co}) \mathrm{O} / \mathrm{SiO}_{2}$ interface. Figure 7 presents a magnification of one of these Co-rich clusters. In the 3D image (fFigure 7a), only $\mathrm{Co}$ and $\mathrm{O}$ atoms are represented for clarity reasons, and the Co cluster is highlighted by a yellow $3 \mathrm{D}$ iso-concentration surface ( $40 \% \mathrm{Co})$. This cluster is indeed located at the $\mathrm{Zn}(\mathrm{Co}) \mathrm{O} / \mathrm{SiO}_{2}$ interface and exhibits a plate shape. This morphology may be due, on the one hand, to 

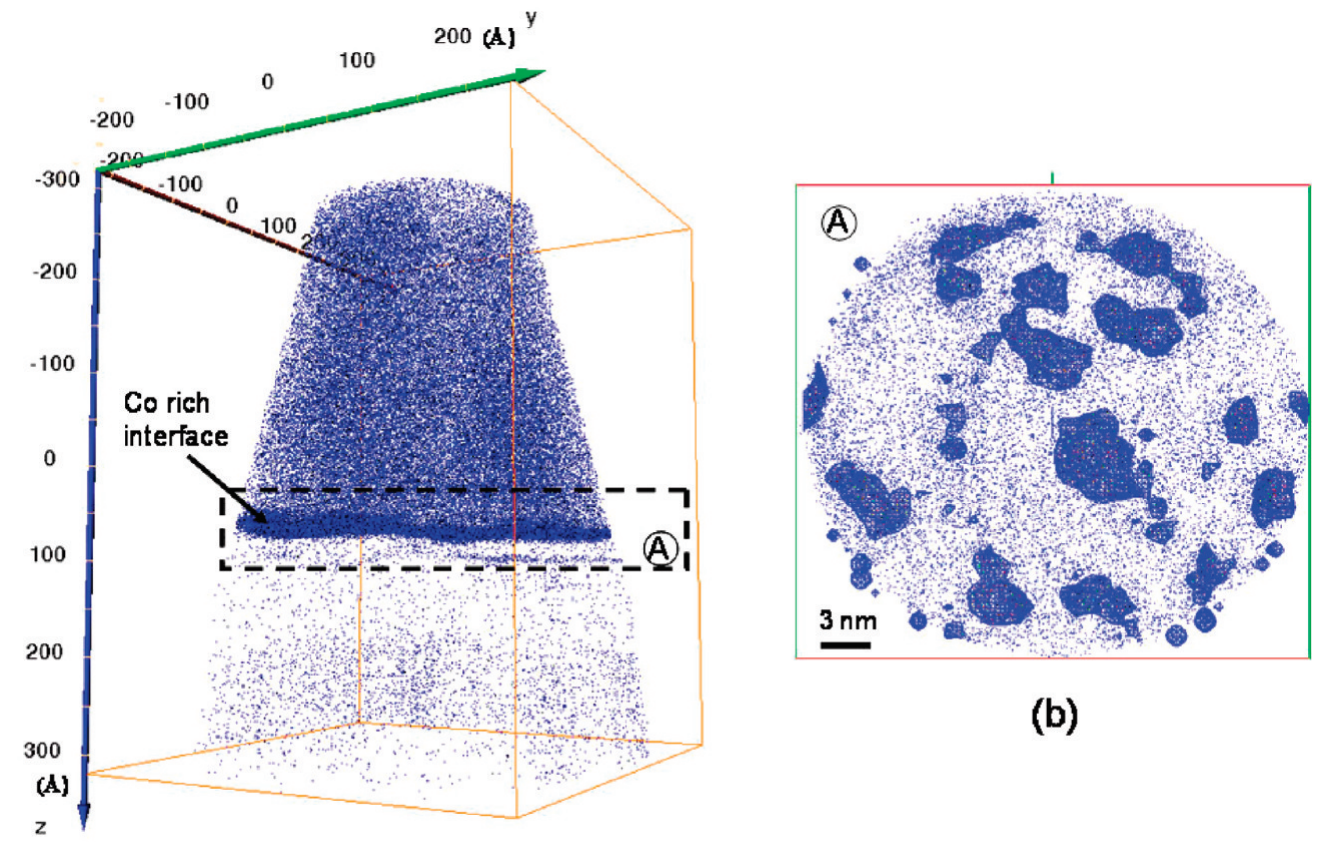

(b)

(a)

Figure 6. (a) Distribution of Co atoms in the analyzed volume of $\mathrm{Zn}_{0.9} \mathrm{Co}_{0.1} \mathrm{O}$; (b) top view of the $\mathrm{Zn}(\mathrm{Co}) \mathrm{O} / \mathrm{SiO}_{2}$ interface: the inhomogeneous distribution of Co atoms is evidenced by iso-concentration filter (threshold: $40 \%$ of $\mathrm{Co}$ ).
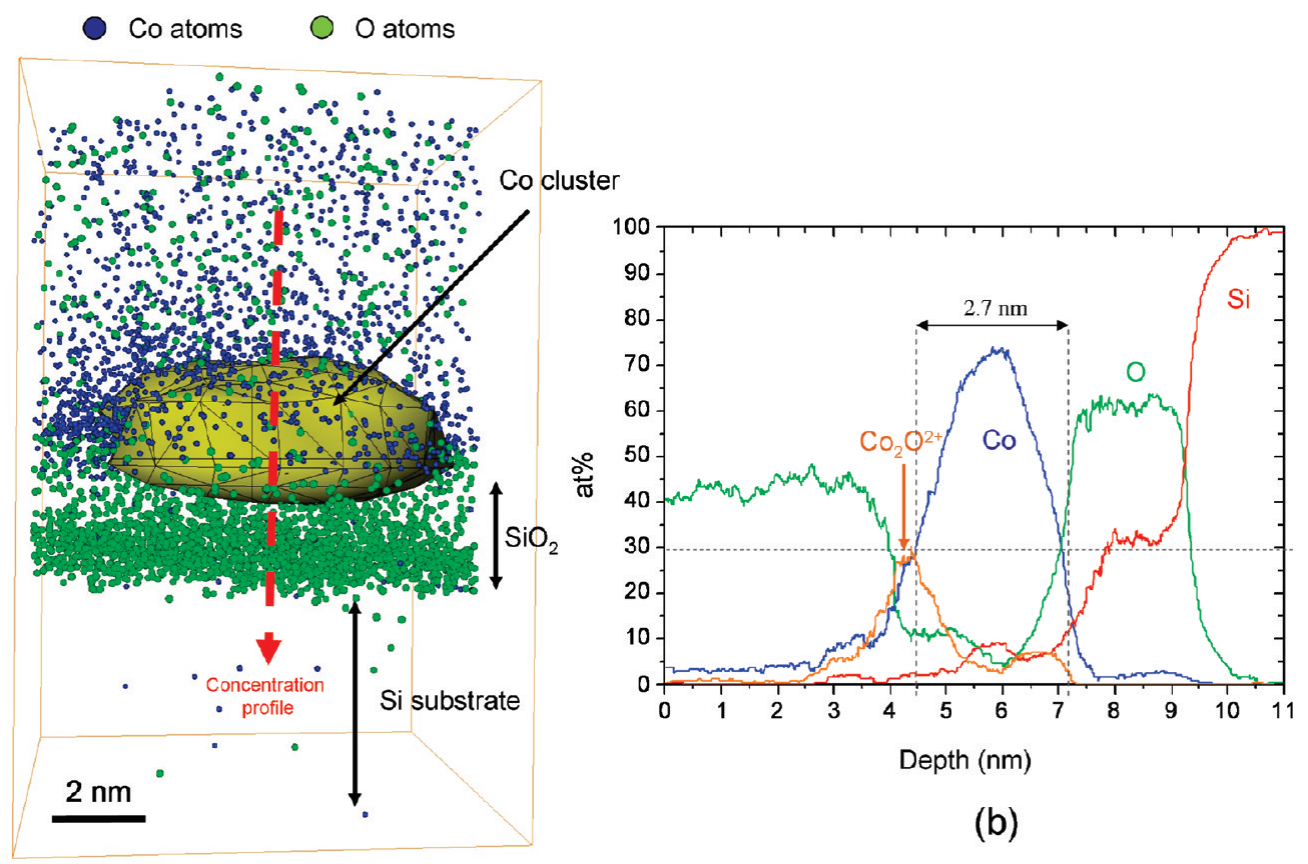

(b)

(a)

Figure 7. (a) $3 \mathrm{D}$ image of a Co cluster grown on the $\mathrm{SiO}_{2}$ layer (in yellow, iso-concentration surface at $30 \mathrm{Co}$ at. \%); (b) concentration profile through the Co cluster along the red arrow in (a).

the location of the cluster (standard lens shape is observed for heterogeneous precipitation on planar defects) and, on the other hand, to a local magnification effect ${ }^{65}$ caused by the large difference in the evaporation fields between the different phases present at the interface. Nevertheless, the thickness of the cluster, which is not affected by the local magnification effect, can be estimated at a value slightly smaller than $3 \mathrm{~nm}$. This value is in good agreement with the value extracted from the magnetization measurements. Figure $7 \mathrm{~b}$ shows the concentration profile through the Co cluster perpendicularly to the interface. For clarity reasons, the $\mathrm{O}, \mathrm{Co}, \mathrm{Co}_{2} \mathrm{O}^{2+}$, and $\mathrm{Si}$ profiles are only shown. The $\mathrm{Si}$ substrate and the $\mathrm{SiO}_{2}$ layer are clearly observed. The concentration of the Co cluster reaches about $75 \%$ of Co in the core. The $\mathrm{Co}_{2} \mathrm{O}^{2+}$ profile corresponds to the molecular $\mathrm{Co}_{2} \mathrm{O}^{2+}$ 

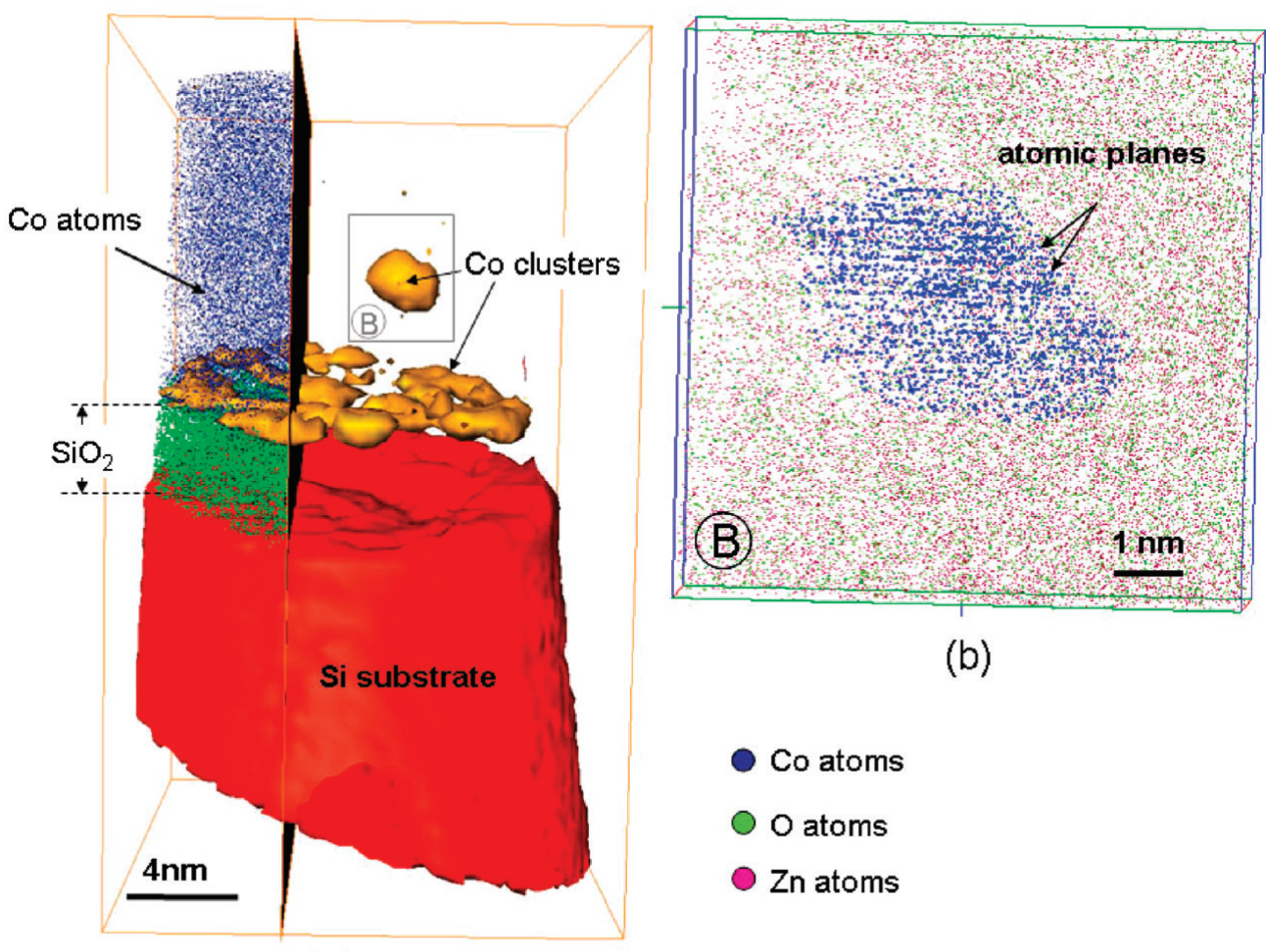

(b)

(a)

Figure 8. (a) 3D image of the cluster decoration of the $\mathrm{Zn}(\mathrm{Co}) \mathrm{O} /$ substrate interface (in yellow, iso-concentration surface at $30 \mathrm{Co}$ at. \%); (b) magnification of the Co cluster in region B.

ions detected in the mass spectrum. The presence of $\mathrm{Co}_{2} \mathrm{O}^{2+}$ is mainly observed at the upper surface of the Co cluster, which suggests the presence of a thin cobalt oxide layer covering the cluster.

This result shows that the nanosized clusters formed at the $\mathrm{Zn}(\mathrm{Co}) \mathrm{O} /$ substrate interface contain more than $70 \%$ of Co. However, as the local magnification effect leads to an artificial chemical mixing (some $\mathrm{O}, \mathrm{Zn}$, and $\mathrm{Si}$ atoms appear as within the cluster whereas they are nearby), it is probable that the observed clusters are almost pure in $\mathrm{Co}$, as was already observed for $\mathrm{Si}$ nanoclusters in $\mathrm{SiO}_{2}$.

These analyses have also revealed the presence of Co clusters at some nanometers above the interface. Figure 8 presents a 3D reconstruction where the Co clusters are imaged by $3 \mathrm{D}$ isoconcentration surfaces. The full decoration of the interface by nanosized Co clusters is once again clearly evidenced. In addition, a Co cluster with a diameter of about $4 \mathrm{~nm}$ can be observed $6 \mathrm{~nm}$ above the interface. Inside this cluster, some Co atomic planes are imaged, indicating the cluster crystallization. Moreover, the local concentration measurements show that this cluster is pure, that is, contains only Co. This result shows that metallic cobalt clusters can be formed near the $\mathrm{Zn}(\mathrm{Co}) \mathrm{O} /$ substrate interface. The aggregation of a nanoscaled Co phase at the interface was already reported by Fukuma et al. in sputtered $\mathrm{Zn}(\mathrm{Co}) \mathrm{O}$ thin films with $20 \mathrm{Co}$ at. \%. ${ }^{31}$ Indeed, the investigation of these films by X-ray magnetic circular dichroism suggested the presence of Co clusters in the film, especially near the substrate. According to Fukuma ${ }^{31,66}$ and Wei, ${ }^{45}$ the formation of these clusters could be related to the presence of oxygen vacancies. Similar results (i.e., paramagnetic clusters near the interface) were also obtained on Co-doped $\mathrm{TiO}_{2}$ films obtained by PLD under vacuum ${ }^{67}$ or low oxidizing pressure. ${ }^{42}$
The atom probe analyses have evidenced the presence of nanosized Co clusters close to the interfaces with the Si substrate and revealed the decoration of the $\mathrm{Zn}(\mathrm{Co}) \mathrm{O} / \mathrm{SiO}_{2}$ interface by a Co cluster assembly. The cluster density was estimated from the data set at about $2.5 \times 10^{11}$ cluster $/ \mathrm{cm}^{2}$. This observation is consistent with the superparamagnetic relaxation evidenced by the ZFC/FC magnetization curves. Indeed, the size of the Co clusters $(3-4 \mathrm{~nm})$ observed by atom probe shows unambiguously that all Co clusters exhibit a superparamagnetic behavior at room temperature. This result is a direct evidence of the superparamagnetic Co clusters suggested by Wei et al. ${ }^{45}$ and shows that these clusters can not be responsible for the room temperature ferromagnetism in $\mathrm{PLD} \mathrm{Zn}_{0.9} \mathrm{Co}_{0.1} \mathrm{O}$ thin films.

A $\mathrm{Zn}_{0.9} \mathrm{Co}_{0.1} \mathrm{O}$ layer has been elaborated by pulsed laser deposition and chemically analyzed at the atomic scale to give an accurate 3D image of the spatial distribution of Co atoms in the $\mathrm{ZnO}$ thin film. XRD results show that the $\mathrm{Zn}_{0.9} \mathrm{Co}_{0.1} \mathrm{O}$ thin film is well crystallized and grown almost epitaxially with a $c$-axis perpendicular to the film plane. The investigation of the magnetic properties shows that the as-deposited $\mathrm{Zn}_{0.9} \mathrm{Co}_{0.1} \mathrm{O}$ is ferromagnetic at room temperature. Atom probe analyses show that the spatial distribution of $\mathrm{Co}$ atoms inside the $\mathrm{Zn}(\mathrm{Co}) \mathrm{O}$ layer is homogeneous. There is no experimental evidence of the presence of any secondary phase such as $\mathrm{CoZn}$ or oxide as $\mathrm{Co}_{3} \mathrm{O}_{4}$. Moreover, the presence of nanosized Co clusters $(\varnothing \approx$ $3-4 \mathrm{~nm})$ at the $\mathrm{Zn}(\mathrm{Co}) \mathrm{O} /$ substrate interface was revealed. The size distribution of this Co cluster assembly is well correlated to the superparamagnetic relaxation evidenced by $\mathrm{ZFC} / \mathrm{FC}$ magnetization measurements.

Thus, the room temperature ferromagnetic properties of the sample studied in this paper can be attributed neither to the 
presence of secondary phases nor to the observed Co clusters, which exhibit a superparamagnetic behavior at room temperature. In the present debate on the origin of the ferromagnetism in Co-doped $\mathrm{ZnO}$ thin film, our results support the defects-induced ferromagnetism models in which oxygen vacancies and/or interstitial defects are needed to obtain a ferromagnetic signal. ${ }^{68,69}$ Finally, the PLD technique does not seem to be well adapted for the growth of Co doped $\mathrm{ZnO}$ films as long as the pressure of the oxidizing atmosphere during deposition is too small (here smaller than $2.8 \times 10^{-6}$ mbar of $\mathrm{N}_{2} / \mathrm{O}_{2}$ ) because Co clusters can be easily formed in these conditions. Therefore, an optimized pressure should be used during deposition such that the formation of Co clusters is avoided but still allowed is the creation of defects, like oxygen vacancies, which are important for the observation of the ferromagnetism.

\section{AUTHOR INFORMATION}

\section{Corresponding Author}

rodrigue.larde@univ-rouen.fr

\section{ACKNOWLEDGMENT}

P. Panissod is warmly acknowledged for fruitful discussions, unraveling the analysis of $\mathrm{ZFC} / \mathrm{FC}$, and correcting the expressions in ref 59, leading to eq 2. D. Ledue is also acknowledged for fruitful discussions.

\section{REFERENCES}

(1) Chambers, S. A. Surf. Sci. Rep. 2006, 61, 345-381.

(2) Pearton, S. J.; Norton, D. P.; Ivill, M. P.; Hebard, A. F.; Zavada, J. M.; Chen, W. M.; Buyanova, I. A. J. Electron. Mater. 2007, 36, 462-471.

(3) Matsukura, F.; Ohno, H.; Shen, A.; Sugawara, Y. Phys. Rev. B 1998, 57, R2037 LP-R2040.

(4) Wang, K. Y.; Campion, R. P.; Edmonds, K. W.; Sawicki, M.; Dietl, T.; Foxon, C. T.; Gallagher, B. L. In Magnetism in ( $G a, M n)$ As Thin Films With $T_{C}$ Up To 173 K; Jose, M., Chris, G. V. d. W., Eds.; AIP: Flagstaff, 2005; pp 333-334.

(5) Dietl, T.; Ohno, H.; Matsukura, F.; Cibert, J.; Ferrand, D. Science 2000, 287, 1019-1022.

(6) Sato, K.; Katayama-Yoshida, H. Jpn. J. Appl. Phys. 2000, 39, L555.

(7) Ogale, S. B. Adv. Mater. 2010, 22, 3125.

(8) Chang, G. S.; Kurmaev, E. Z.; Boukhvalov, D. W.; Finkelstein, L. D.; Moewes, A.; Bieber, H.; Colis, S.; Dinia, A. J. Phys.: Condens. Matter 2009, 21, 056002.

(9) Ndilimabaka, H.; Colis, S.; Schmerber, G.; Müller, D.; Grob, J. J.; Gravier, L.; Jan, C.; Beaurepaire, E.; Dinia, A. Chem. Phys. Lett. 2006, 421, 184-188.

(10) Han, S. J.; Jang, T. H.; Kim, Y. B.; Park, B. G.; Park, J. H.; Jeong, Y. H. Appl. Phys. Lett. 2003, 83, 920-922.

(11) Alaria, J.; Bieber, H.; Colis, S.; Schmerber, G.; Dinia, A. Appl. Phys. Lett. 2006, 88, 112503-3.

(12) Bouloudenine, M.; Viart, N.; Colis, S.; Dinia, A. Catal. Today 2006, 113, 240-244.

(13) Sati, P.; Hayn, R.; Kuzian, R.; Régnier, S.; Schäfer, S.; Stepanov, A.; Morhain, C.; Deparis, C.; Laügt, M.; Goiran, M.; Golacki, Z. Phys. Rev. Lett. 2006, 96, 017203.

(14) Colis, S.; Bieber, H.; Bégin-Colin, S.; Schmerber, G.; Leuvrey, C.; Dinia, A. Chem. Phys. Lett. 2006, 422, 529-533.

(15) Belghazi, Y.; Schmerber, G.; Colis, S.; Rehspringer, J. L.; Berrada, A.; Dinia, A. J. Magn. Magn. Mater. 2007, 310, 2092-2094.

(16) Potzger, K.; Shalimov, A.; Zhou, S.; Schmidt, H.; Mucklich, A.; Helm, M.; Fassbender, J.; Liberati, M.; Arenholz, E. J. Appl. Phys. 2009, 105, 123917-8.

(17) Bouloudenine, M.; Viart, N.; Colis, S.; Kortus, J.; Dinia, A. Appl. Phys. Lett. 2005, 87, 052501.
(18) Jedrecy, N.; von Bardeleben, H. J.; Zheng, Y.; Cantin, J. L. Phys. Rev. B 2004, 69, 041308.

(19) Jin, Z.; Fukumura, T.; Kawasaki, M.; Ando, K.; Saito, H.; Sekiguchi, T.; Yoo, Y. Z.; Murakami, M.; Matsumoto, Y.; Hasegawa, T.; Koinuma, H. Appl. Phys. Lett. 2001, 78, 3824-3826.

(20) Kim, J. H.; Kim, H.; Kim, D.; Ihm, Y. E.; Choo, W. K. J. Appl. Phys. 2002, 92, 6066-6071.

(21) Lawes, G.; Risbud, A. S.; Ramirez, A. P.; Seshadri, R. Phys. Rev. B 2005, 71, 045201.

(22) Sati, P.; Schäfer, S.; Morhain, C.; Deparis, C.; Stepanov, A. Superlattices Microstruct. 2007, 42, 191-196.

(23) Dinia, A.; Schmerber, G.; Meny, C.; Pierron-Bohnes, V.; Beaurepaire, E. J. Appl. Phys. 2005, 97, 123908.

(24) Dinia, A.; Schmerber, G.; Pierron-Bohnes, V.; Mény, C.; Panissod, P.; Beaurepaire, E. J. Magn. Magn. Mater. 2005, 286, 37-40.

(25) Ueda, K.; Tabata, H.; Kawai, T. Appl. Phys. Lett. 2001, 79, 988.

(26) Kittilstved, K. R.; Norberg, N. S.; Gamelin, D. R. Phys. Rev. Lett. 2005, 94, 147209-4.

(27) Prellier, W.; Fouchet, A.; Simon, C.; Mercey, B. Mater. Sci. Eng., B 2004, 109, 192-195.

(28) Rode, K.; Anane, A.; Mattana, R.; Contour, J.-P.; Durand, O.; LeBourgeois, R. J. Appl. Phys. 2003, 93, 7676-7678.

(29) Norton, D. P.; Overberg, M. E.; Pearton, S. J.; Pruessner, K.; Budai, J. D.; Boatner, L. A.; Chisholm, M. F.; Lee, J. S.; Khim, Z. G.; Park, Y. D.; Wilson, R. G. Appl. Phys. Lett. 2003, 83, 5488-5490.

(30) Jung, S. W.; An, S. J.; Gyu-Chul, Y.; Jung, C. U.; Sung-Ik, L.; Sunglae, C. Appl. Phys. Lett. 2002, 80, 4561-4563.

(31) Fukuma, Y.; Asada, H.; Yamamoto, J.; Odawara, F.; Koyanagi, T. Appl. Phys. Lett. 2008, 93, 142510-3.

(32) Jung, H. P.; Min, G. K.; Hyun, M. J.; Sangwoo, R.; Young, M. K. Appl. Phys. Lett. 2004, 84, 1338-1340.

(33) Sun, Z.; Yan, W.; Zhang, G.; Oyanagi, H.; Wu, Z.; Liu, Q.; Wu, W.; Shi, T.; Pan, Z.; Xu, P.; Wei, S. Phys. Rev. B 2008, 77, 245208.

(34) Lee, H. J.; Choi, S. H.; Cho, C. R.; Kim, H. K.; Jeong, S. Y. Europhys. Lett. 2005, 76.

(35) Park, J. H.; Kim, M. G.; Jang, H. M.; Ryu, S.; Kim, Y. M. Appl. Phys. Lett. 2004, 84, 1338-1340.

(36) Prellier, W.; Fouchet, A.; Mercey, B. J. Phys.: Condens. Matter 2003, 15, R1583-R1601.

(37) Song, C.; et al. J. Phys.: Condens. Matter 2007, 19, 176229.

(38) Kundaliya, D. C.; Ogale, S. B.; Lofland, S. E.; Dhar, S.; Metting, C. J.; Shinde, S. R.; Ma, Z.; Varughese, B.; Ramanujachary, K. V.; Salamanca-Riba, L.; Venkatesan, T. Nat. Mater. 2004, 3, 709-714.

(39) Coey, J. M. D.; Venkatesan, M.; Fitzgerald, C. B. Nat. Mater. 2005, 4, 173-179.

(40) Pemmaraju, C. D.; Hanafin, R.; Archer, T.; Braun, H. B.; Sanvito, S. Phys. Rev. B 2008, 78, 054428.

(41) Shinde, S. R.; Ogale, S. B.; Higgins, J. S.; Zheng, H.; Millis, A. J.; Kulkarni, V. N.; Ramesh, R.; Greene, R. L.; Venkatesan, T. Phys. Rev. Lett. 2004, 92, 166601.

(42) Kim, D. H.; Yang, J. S.; Lee, K. W.; Bu, S. D.; Noh, T. W.; Oh, S. J.; Kim, Y. W.; Chung, J. S.; Tanaka, H.; Lee, H. Y.; Kawai, T. Appl. Phys. Lett. 2002, 81, 2421-2423.

(43) Sharma, P.; Gupta, A.; Rao, K. V.; Owens, F.J.; Sharma, R; Ahuja, R; Guillen, J. M. O.; Johansson, B.; Gehring, G. A. Nat. Mater. 2003, 2, 673-677.

(44) Rode, K.; Mattana, R.; Anane, A.; Cros, V.; Jacquet, E.; Contour, J.-P.; Petroff, F.; Fert, A.; Arrio, M.-A.; Sainctavit, P.; Bencok, P.; Wilhelm, F.; Brookes, N. B.; Rogalev, A. Appl. Phys. Lett. 2008, 92, 012509-3.

(45) Wei, H.; Yao, T.; Pan, Z.; Mai, C.; Sun, Z.; Wu, Z.; Hu, F.; Jiang, Y.; Yan, W. J. Appl. Phys. 2009, 105, 043903-6.

(46) Barla, A.; Schmerber, G.; Beaurepaire, E.; Dinia, A.; Bieber, H.; Colis, S.; Scheurer, F.; Kappler, J.-P.; Imperia, P.; Nolting, F.; Wilhelm, F.; Rogalev, A.; Muller, D.; Grob, J. J. Phys. Rev. B: Condens. Matter Mater. Phys. 2007, 76, 125201-5.

(47) Gacic, M.; Jakob, G.; Herbort, C.; Adrian, H.; Tietze, T.; Bruck, S.; Goering, E. Phys. Rev. B: Condens. Matter Mater. Phys. 2007, 75, 205206-8. 
(48) Gault, B.; Vurpillot, F.; Vella, A.; Gilbert, M.; Menand, A.; Blavette, D.; Deconihout, B. Rev. Sci. Instrum. 2006, 77, 043705.

(49) Larde, R.; Talbot, E.; Vurpillot, F.; Pareige, P.; Schmerber, G.; Beaurepaire, E.; Dinia, A.; Pierron-Bohnes, V. J. Appl. Phys. 2009, 105, 126107.

(50) Talbot, E.; Larde, R.; Gourbilleau, F.; Dufour, C.; Pareige, P. Europhys. Lett. 2009, 87, 26004.

(51) Blavette, D.; Deconihout, B.; Bostel, A.; Sarrau, J. M.; Bouet, M.; Menand, A. Rev. Sci. Instrum. 1993, 64, 2911-2919.

(52) Cerezo, A.; Godfrey, T. J.; Smith, G. D. W. Rev. Sci. Instrum. 1988, 59, 862-866.

(53) Miller, M. K.; Forbes, R. G. Mater. Charact. 2009, 60, 461-469.

(54) Ronsheim, P. A.; Hatzistergos, M.; Jin, S. J. Vac. Sci. Technol., B 2010, 28, C1E1-C1E4.

(55) Larde, R.; Bran, J.; Jean, M.; Le Breton, J. M. Powder Technol. 2010, doi:10.1016/j.powtec.2010.08.014.

(56) Larde, R.; Lechevallier, L.; Zarefy, A.; Bostel, A.; Juraszek, J.; Le Breton, J. M.; Rodmacq, B.; Dieny, B. J. Appl. Phys. 2009, 105, 084307.

(57) Kodzuka, M.; Ohkubo, T.; Hono, K.; Matsukura, F.; Ohno, H. Ultramicroscopy 2009, 109, 644-648.

(58) Grenier, A.; Larde, R; Cadel, E.; Vurpillot, F.; Juraszek, J.; Teillet, J.; Tiercelin, N. J. Appl. Phys. 2007, 102, 033912.

(59) Duguay, S.; Vurpillot, F.; Philippe, T.; Cadel, E.; Larde, R.; Deconihout, B.; Servanton, G.; Pantel, R. J. Appl. Phys. 2009, 106, 106102.

(60) Blavette, D.; Al Kassab, T.; Cadel, E.; Mackel, A.; Vurpillot, F.; Gilbert, M.; Cojocaru, O.; Deconihout, B. Int. J. Mater. Res. 2008, 99, 454-460.

(61) Thompson, G. B.; Miller, M. K.; Fraser, H. L. Ultramicroscopy 2004, 100, 25-34.

(62) Bean, C. P.; Livingston, J. D. J. Appl. Phys. 1959, 30, S120-S129.

(63) Chantrell, R. W.; El-Hilo, M.; O'Grady, K. IEEE Trans. Magn. 1991, 27, 3570.

(64) Denardin, J. C.; Brandl, A. L.; Knobel, M.; Panissod, P.; Pakhomov, A. B.; Liu, H.; Zhang, X. X. Phys. Rev. B 2002, 65, 064422.

(65) Vurpillot, F.; Bostel, A.; Blavette, D. Appl. Phys. Lett. 2000, 76, 3127-3129.

(66) Fukuma, Y.; Odawara, F.; Asada, H.; Koyanagi, T. Phys. Rev. B 2008, 78, 104417.

(67) Shinde, S. R. Phys. Rev. Lett. 2004, 92, 166601.

(68) Coey, J. M. D. Curr. Opin. Solid State Mater. Sci. 2006, 10, 83-92.

(69) Raebiger, H.; Lany, S.; Zunger, A. Phys. Rev. B 2009, 79, 165202. 